\title{
Seismic site response of unstable steep slope using noise measurements: the case study of Xemxija Bay area, Malta
}

\author{
F. Panzera ${ }^{1}$, S. D’Amico ${ }^{2}$, A. Lotteri ${ }^{2}$, P. Galea ${ }^{2}$, and G. Lombardo ${ }^{1}$ \\ ${ }^{1}$ Dip. Scienze Biologiche, Geologiche e Ambientali, Università di Catania, Italy \\ ${ }^{2}$ Physics Department, University of Malta, Msida, Malta \\ Correspondence to: F. Panzera (panzerafrancesco@ hotmail.it)
}

Received: 18 April 2012 - Revised: 22 August 2012 - Accepted: 5 September 2012 - Published: 21 November 2012

\begin{abstract}
Landslide phenomena involve the northern coast of Malta, affecting in particular the urban area of Xemxija. Limestones overlying a clayey formation represent the shallower lithotypes that characterize the surficial geology of this area, where lateral spreading phenomena and rockfalls take place.

Ambient noise records, processed through spectral ratio techniques, were analysed in order to characterize the dynamic behavior of the rock masses affected by the presence of fractures linked to the landslide body existing in the area. Experimental spectral ratios were also calculated after rotating the horizontal components of the seismic signal, and a direct estimate of the polarization angle was also performed in order to investigate the existence of directional effects in the ground motion.

The results of the morphologic survey confirmed the existence of large cliff-parallel fractures that cause cliff-edge and unstable boulder collapses. Such phenomena appear connected to the presence, inside the clay formation, of a sliding surface that was identified through the interpretation of the noise measurement data. The boundaries of the landslide area appear quite well defined by the pronounced polarization effects, trending in the northeastern direction, observed in the fractured zone and in the landslide body in particular.
\end{abstract}

\section{Introduction}

The Maltese Archipelago is situated in the Mediterranean Sea, about $290 \mathrm{~km}$ northeast of Tunisia and $90 \mathrm{~km}$ south of Sicily. It consists of three major islands: Malta and Gozo, the southerly and northerly islands, respectively, and Comino, which lies in the Comino Straits separating the two largest islands (Fig. 1). The Maltese economy is mainly based on the tourism industry and has increased since the 1970s with a high degree of coastal urban settlements.

In order to better preserve the historical heritage, landscapes, and coastal areas and to promote tourism activities, it has been proposed that the archipelago might be considered as an open air laboratory. In this context multidisciplinary studies integrating geology, engineering, geomorphology as well as history and archeology may be undertaken in order to develop and test methodologies for the assessment of the relationship between the physical environment and cultural heritage (Soldati et al., 2008).

Xemxija is a seaside village and marina on the northeastern part of Malta (Fig. 1), and it is a very important site for touristic attractions, as well as cultural and historical heritage. In fact, up Xemxija Hill lies what is known as The Xemxija Heritage Trail, which comprises a variety of sites spanning a period of about $6000 \mathrm{yr}$ (e.g. seven prehistoric tombs, a Neolithic temple, a Roman road, several caves, an ancient and well-preserved Roman apiary, a Punic tomb, Roman baths, a 1000 yr old carob tree, etc.). The Xemxija study area spans a couple of square kilometres. More than half of it is intensely built, while the remaining area consists of meadows and agricultural land. The area is characterized by a geology and topography that varies over small spatial scales. Its geomorphological features are the result of the combined effect of the lithology, tectonics and coastal nature that shaped the region, and such features contribute towards the degree of geological instability of the whole area and particularly to the cliff sections.

To date, no studies combining geomorphology and site response have been carried out in the study area of Xemxija. In this paper we carried out a preliminary study of the area, 


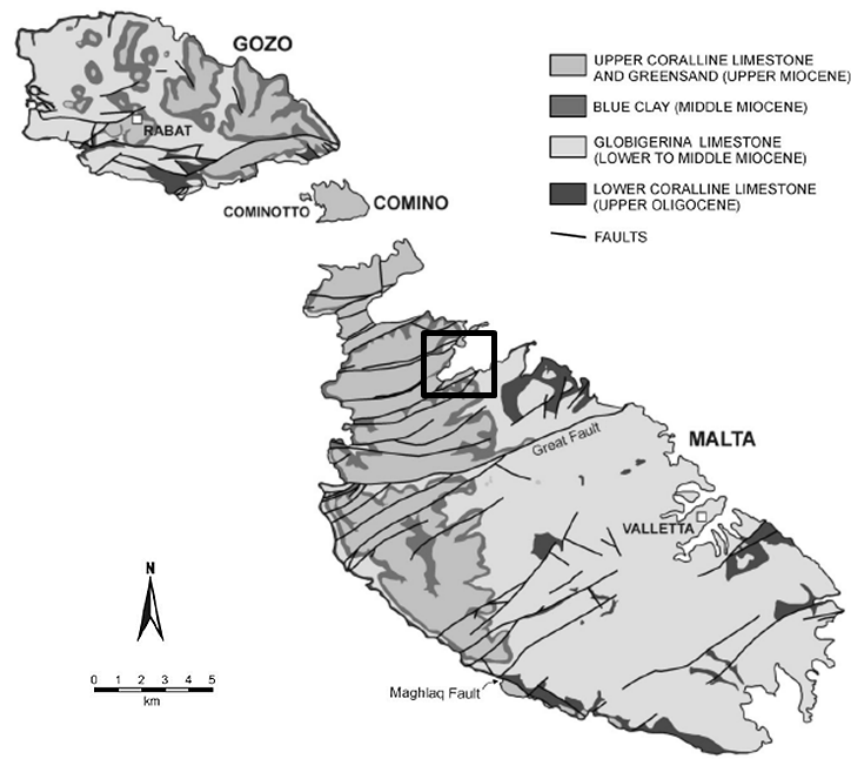

Fig. 1. Sketched geological map of the Maltese Islands (modified from Various Authors, 1993). The black square indicates the study area.

paying particular attention to the risk of landsliding and rockfalls. In particular, the combination of vulnerable geomorphological features, intensive land use and cultural/touristic importance implies that the study area is exposed to a considerable natural risk. Buildings in Xemxija village are located in a diversity of topographical settings, such as slopes, ridges and valleys, while a variety of building types and ages can be identified. The small urban settlement is densely populated in summer, when it is used as a summer resort with intensive recreational and commercial coastal land use. The area also provides a suitable setting for the subsequent evaluation of a number of other factors that contribute to the damage potential, and hence the holistic assessment of geo-risks.

We have conducted a qualitative geomorphological survey of the area, and we used the ambient noise horizontal-tovertical spectral ratio (HVSR) technique in order to characterize the behavior of rock masses in the presence of fractures linked to the landslide body in the area. This type of measurement can be done quickly and with a high spatial density, providing a fast tool for setting the dynamic behavior of the rock outcropping in Xemxija. Recordings of ambient noise and the use of the HVSR technique have recently had widespread use in studying landslides (e.g. Del Gaudio et al., 2008; Burjánek et al., 2010; Del Gaudio and Wasowski 2011; Burjánek et al., 2012).

\section{Geological setting}

The geology of the Maltese islands is relatively young, with the oldest rock dating back only to the Tertiary period. The islands are mostly composed of marine sedimentary rocks
(Fig. 1). Although the sedimentary platform on which the Maltese islands are situated was formed during the Triassic, there are no surface outcrops of this age. All exposed rocks were deposited during the Oligocene and Miocene when the Maltese Islands were part of the Malta-Ragusa platform with Sicily and, as such, attached to the African margin (Pedley et al., 1978; Mourik et al., 2011). The most recent deposits are the Quaternary deposits, which are found in minor quantities and are of terrestrial origin. The geologic sequence of the Maltese Islands is classically divided into five units (Pedley et al., 1978, 2002). The lowermost unit is the Lower Coralline Limestone Formation (LCL), which consists of massive biogenic limestone beds of shallow gulf marine origin. This shallow carbonate ramp phase is Oligocene in age. Younger beds show evidence of deposition in more open marine conditions. Deeper water slope carbonates of the Globigerina Limestone Formation (GL) began depositing in the Chattian (Late Oligocene) and span from the early Miocene to late middle Miocene. They consist mainly of loosely aggregated planktonic foraminifers, whereas larger skeletal fragments, such as echinoids or mollusks, are rare. A marly unit of alternating light to dark layers, called the Blue Clay Formation (BC), spanning the Serravalian (middle Miocene) (Kienel et al., 1995; Jacobs et al., 1996), abruptly follows the GL. Planktonic and benthic foraminifers form the bulk of the skeletal components within this unit. The water depth at which $\mathrm{BC}$ was formed is estimated on the basis of benthic foraminifers to be 150-200 m (Jacobs et al., 1996), or even $500 \mathrm{~m}$ (Foresi et al., 2002). The BC formation is unconformably overlain by the Greensand Formation (GS) and the Upper Coralline Limestone Formation (UCL), both late Miocene in age. The GS formation consists of a glauconitic sand bed ranging from 0 to $10 \mathrm{~m}$ in thickness, while the UCL consists of white porous calcareous sandstone, always rich in organic remains. Though some layers are completely crystalline and have lost traces of the organisms from which they originated, other portions are highly fossiliferous containing casts of shells and other organisms. It resembles the LCL both on chemical and paleontological grounds, indicating deposition in shallow-water carbonate ramp conditions.

On Malta and Gozo, the bedding is generally subhorizontal, with a maximum dip of about $5^{\circ}$. The geostructural pattern is dominated by two intersecting fault systems which alternate in tectonic activity. An older ENEWSW trending fault, the Victoria Lines Fault (or Great Fault), traverses the islands and is crossed by a younger NWSE trending fault, the Maghlaq Fault (Fig. 1), parallel to the Malta Trough, which is the easternmost graben of the Pantelleria Rift System. The faults belonging to the older set, all vertical or sub-vertical, are part of a horst and graben system of relatively small vertical displacement. The structural geology of the Maltese Islands is usually divided into three main regions: north of the Victoria Lines fault, south of the Victoria Lines fault and Gozo. The Xemxija Bay study area lies north of the Victoria Lines fault, where the structure is 
dominated by the development of horst and graben blocks, bounded by ENE trending normal faults; it is characterized by three different lithotypes: clay from the $\mathrm{BC}$ formation and two different members of the UCL formation, namely, the Tal-Pitkal Member, which is hard and pitted, and the Mtarfa Member, more soft and erodible. The coast north of the Victoria Lines Fault in Malta is characterized by lateral spreading phenomena which take place within the brittle and heavily jointed and faulted UCL formation overlying the BC formation, consisting of softer and unconsolidated material. Most of the time these processes occur in places that are not intensively built, however some areas are highly frequented by both local and tourists for recreation activities.

\section{Geomorphologic analysis}

The study of slope instability conditions in the coastal region of Malta is an important task since several areas are subject to a high landslide hazard. Coastal erosion, generally, takes place in conditions of poor sediment availability and when the sea engulfs the land due to wind, wave and tidal pressures (Doody et al., 2004; Young et al., 2011). This erosion process can include three simultaneous processes, namely, the long-term retreat of coasts, the medium-term degradation of beaches and the short-term cliff erosion (Hart, 1986). Geomorphologic studies were conducted by Magri et al. (2008) on the west coast of Malta and in Gozo, which share similar geological conditions. Along the west coast of Malta, in particular, a temporary GPS network was set up in 2005 to monitor the state of the lateral spreading activity, and preliminary results indicate that the coastal landslides are quite active. A number of preliminary field surveys of the NW and NE coasts of Malta were carried out by Farrugia (2008) and Coratza et al. (2011) to better understand Maltese coastal development and to highlight areas having similar geological features. Landslides in the northern Malta coast seem to be caused by lateral spreading and rockfall (Fig. 2a), which occur within the brittle UCL formation overlying the BC. The UCL formation is characterized by a prominent plateau scarp face, whereas $\mathrm{BC}$ produces slopes extending from the base of the UCL scarp face to sea level. It is well known that lateral spreading usually takes place in the lateral extension of cohesive rock masses lying over a deforming mass of softer material where the controlling basal shear surface is often not well defined (Pasuto and Soldati, 1996).

A detailed field survey was performed in the Xemxija Bay area to map the main coastal instability features, using a map at scale $1: 2500$ (MEPA, 2004). The features mapped are the result of different mechanisms, such as:

- cliff parallel fracturing due to natural cliff erosion and retreat;

- formation and detachment of blocks along the cliff edge, leading to rock collapse;

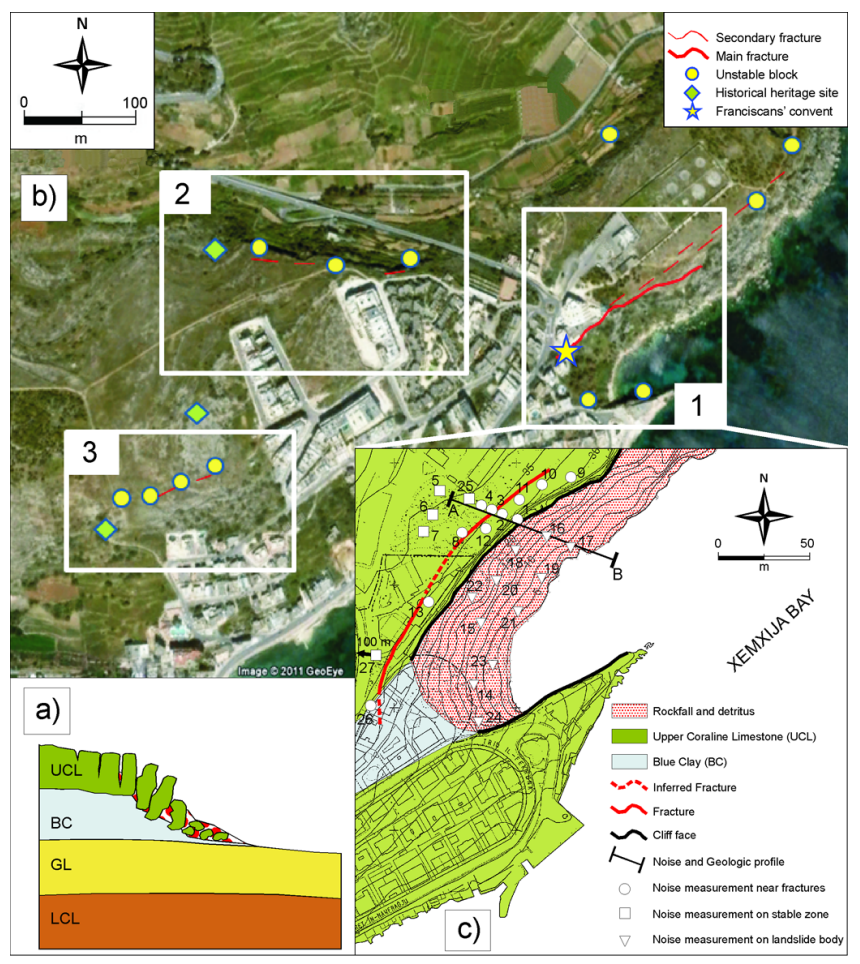

Fig. 2. (a) Schematic sketch of lateral spreading effects along the Xemxija coast; (b) view of the Xemxija Bay area showing the sites investigated in the geomorphological survey; and (c) geo-lithologic map of the northeastern part of the Xemxija Bay (modified from Various Authors, 1993).

- landsliding on sloping faces; and

- instability resulting from weakening of the UCL strata lying on the top of the soft BC layer that is slowly eroding and sliding.

In the study area, attention was particularly focused on fractures and unstable blocks existing along the coastline and the hill (see areas 1, 2, 3 in Fig. 2b).

Along the Xemxija cliff and headland, in the UCL formation, a main fracture, striking in the NE-SW direction, is quite evident (area 1 of Fig. 2b). It develops along the southwestern end of the cliff coast at a variable distance (1-8 m) from the cliff edge, and it is sometimes filled with rock debris and soil. The fracture width ranges from less than $10 \mathrm{~cm}$ to about $80 \mathrm{~cm}$, whereas its depth ranges between $1 \mathrm{~m}$ to $1.60 \mathrm{~m}$. A vertical offset ranging from 3 to about $20 \mathrm{~cm}$ was measured in several points. Many secondary fractures run along the cliff in a parallel direction, which is also compatible with the structural system present in the area. All the UCL appears intensively fractured (Fig. 3a and b), and some of the fractures show signs of humidity and fluid percolation. It is fair to say that some zones in the study area could not be mapped because they were covered by thick vegetation. A number of collapsed rocks and detached blocks lie at the base of the cliff 


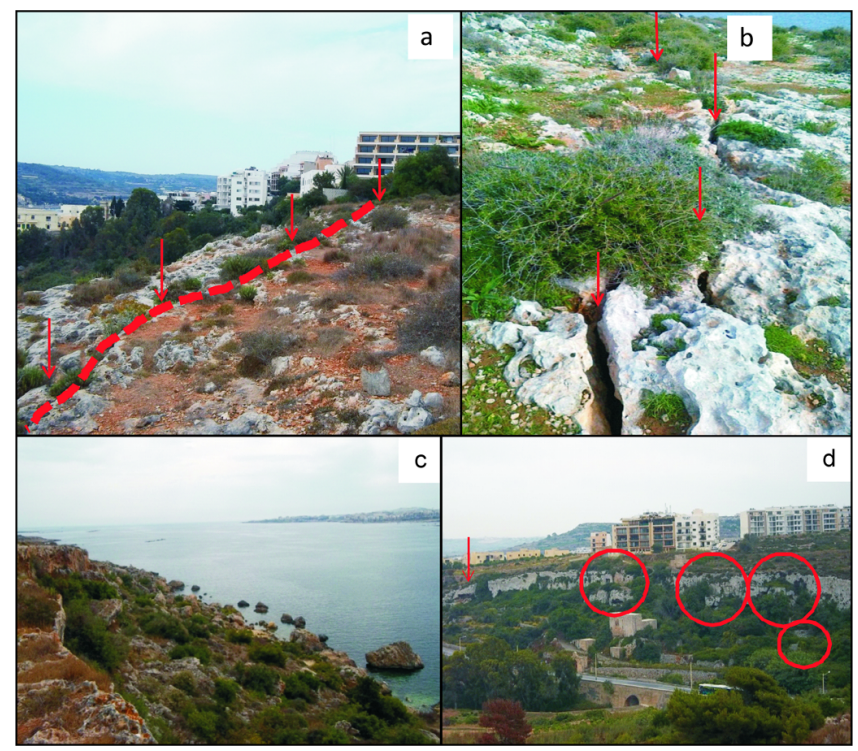

Fig. 3. (a) and (b) Overview, along the cliff area, of the main fracture, which is approximately striking in the NE-SW direction; (c) example of shore area below the cliff (area 1); and (d) overview of the cliff escarpment along the north side of the ridge (area 2).

escarpment and contribute to form much of the shore area, as seen in Fig. 3c.

The hill behind the cliff (area 2 in Fig. $2 b$ ) presents the same stratigraphy and type of structures visible at the cliff edge, with numerous detachments and secondary fractures along both sides of the hill trending in an E-W direction (Fig. 3d). Moreover, several cavities permeate the UCL outcrops (see arrow in Fig. 3d), while discontinuities generate blocks of different sizes, mostly covered by vegetation and showing also the presence of fluid percolation. In this area, huge collapsed blocks, having sizes of up to 7-8 $\mathrm{m}$, lie along the base of the escarpment (circles in Fig. 3d).

On the other side of the hill (area 3 Fig. 2b) the slope is characterized by small-medium size blocks that have been detached from the top UCL formation overlying the BC. No protection measures (e.g. net, walls) have been taken to protect the residential area that lies below. Considering that the hill trends in a NE-SW direction, the same as the cliff, and since the processes that involve the hill are substantially the same as those affecting the cliff, rockfall risk might be a problem for the buildings placed on the foot of the "seaside" slope.

It is important to notice that the main fracture in area 1 (Fig. 2b) identified in the present study runs close to a residential complex and the Franciscans' convent and San Guzepp Haddiem church, as shown in Fig. 2b. In Fig. 3a, the arrows track this fracture which is responsible for several cracks in the walls of the building. Although the religious complex was newly built about $12 \mathrm{yr}$ ago to replace the previous structure which was affected by similar problems, the

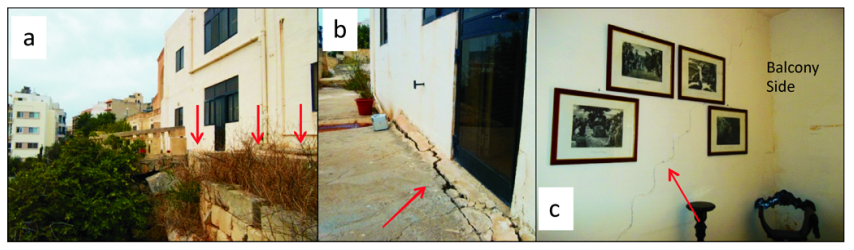

Fig. 4. Cracks and damage in the San Guzepp Haddiem church. (a) The balcony on the southern side of the building; (b) detailed view of the main fracture along the south side of the church; and (c) view of a room inside the building.

complex does present already several major cracks presumably related to the main fracture previously shown in Fig. $2 \mathrm{~b}$. In Fig. 4, the unstable situation prevailing today is shown. It can be indeed observed that the southern part of the building is extensively cracked and perceptibly tilted and, large cracks are also visible on the front balcony (Fig. 4a). Along the south block of the church a wide crack is running in E-W direction (see arrows in Fig. 4b). Besides, in one of the rooms that are overlooking the south coast of the cliff, evidence of cracks can be observed (Fig. 4c). Examining the direction of cracks along the cliff and those on the church, it is plausible to assume that all of the cracks present in this complex are associated with movements taking place in the same group of geological fractures.

The field survey has also pointed out that different hazards exist in different portions of the study area, according to the type of land use. On the beach below the cliff on the headland, a clear hazard from collapsing rocks is present for people making recreational use of the shore. On the northern side of the ridge, where Roman baths and tombs are carved into the Upper Coralline Limestone, most of the slope consists of cultivated fields and meadows. As can be seen in Fig. 3c, the main hazard here is due to potential rockfalls onto the road linking Xemxija to Mellieha that runs along the base of the escarpment. Finally, the slope of the hill on the side of Xemxija Bay, which is increasingly being built up, might be involved in collapsing and sliding.

\section{$4 \mathrm{H} / \mathrm{V}$ measurements}

\subsection{Experimental setup and data processing}

The HVSR method is a common tool used for site effect investigations. It is based on the ratio of the horizontal to vertical components of ground motion. Generally, this spectral ratio exhibits a peak corresponding to the fundamental frequency of the site. The ambient noise wavefield is the result of the combination of unknown fractions of both body and surface waves (Bonnefoy-Claudet et al., 2006). If the first are prevailing, the ratio is mainly induced by $S_{H}$ resonance in the superficial layers whereas; if Rayleigh surface waves predominate, the theoretical ellipticity dictates 
the observed curves (Nogoshi and Igarashi 1970; Fäh et al., 2001; Scherbaum et al., 2003). This is especially true when a large shear wave velocity contrast exists between the shallow layer and the bedrock, as theoretically confirmed by Malischewsky and Scherbaum (2004). Although experimental data peaks usually fit quite well the resonance frequency of the theoretical curves, they are less reliable as regards their amplitude. Nevertheless, the HVSR curve contains valuable information about the underlying structure, especially as concerns the relationship between $V_{\mathrm{S}}$ of the sediments and their thickness (Ibs-Vonseth and Wholenberg 1999; Scherbaum et al., 2003).

We recorded ambient noise at 27 sites (Fig. 2c) using a 3component seismometer (Tromino, www.tromino.eu). Time series of ambient noise, having a length of $20 \mathrm{~min}$, were recorded with a sampling rate of $128 \mathrm{~Hz}$ and, following the guidelines suggested by the SESAME project (2004), they were divided in different time windows of $20 \mathrm{~s}$ each not overlapping each other. A $5 \%$ cosine taper was applied to each window and the Fourier spectra were calculated. The spectra of each window were smoothed using a Konno-Ohmachi window (Konno and Ohmachi, 1998) fixing the parameter $b$ to 40 . Finally, the resulting HVSR, in the frequency range $0.5-40.0 \mathrm{~Hz}$, was computed by estimating the logarithmic average of the spectral ratio obtained for each time window, selecting only the most stationary and excluding transients associated to very close sources.

Experimental spectral ratios were also calculated after rotating the N-S and E-W components of motion by steps of 10 degrees starting from $0^{\circ}$ (north) to $180^{\circ}$ (south). This approach, first applied to earthquake recordings in studying the directional effects due to topographic irregularities at Tarzana, California (Spudich et al., 1996), has been used for ambient noise signals by several authors (e.g. Lermo and Chávez-Garcia, 1993; Panzera et al., 2011a) and to identify site response directivity in the presence of an unstable slope as well (Del Gaudio et al., 2008; Burjánek et al., 2010; Del Gaudio and Wasowisky, 2011).

A direct estimate of the polarization angle was also achieved by using the covariance matrix method (Jurkevics, 1988) to overcome the bias linked to the denominator behavior that could occur in the HVSR technique. This technique is based on the evaluation of eigenvectors and eigenvalues of the covariance matrix obtained by three-component seismograms. Signals at each site were band-pass filtered using the entire recordings and a moving window of $1 \mathrm{~s}$ with $20 \%$ overlap, therefore obtaining the strike of maximum polarization for each moving time window.

\subsection{HVSR patterns and interpretation}

A dense microtremor measurement survey was carried out in the Xemxija Bay area (Fig. 2c). We focused on the NE part of the bay, in which there is major evidence of slope instability and in which a high level of cliff fracturing is evident. We
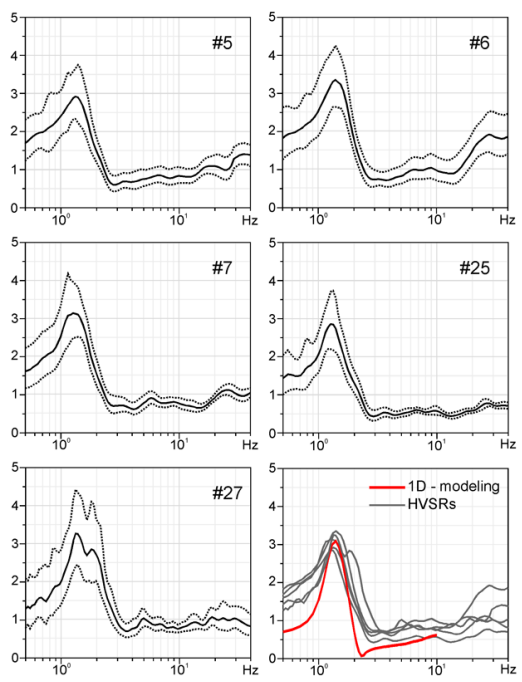

$\# 27$
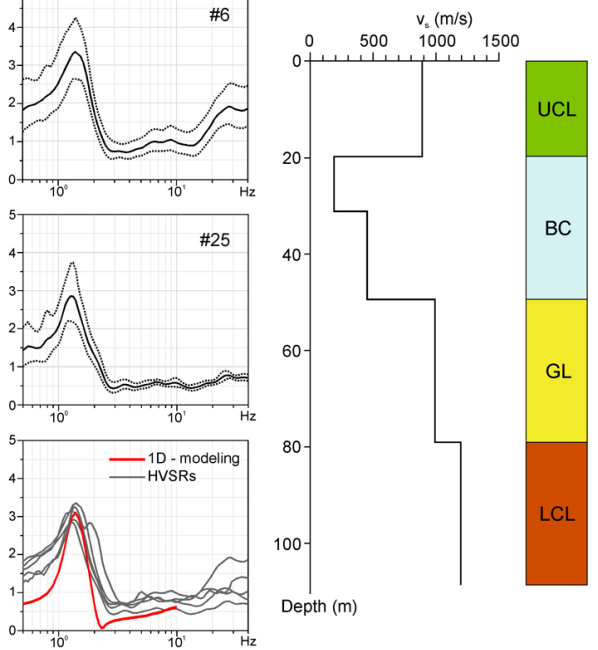

Fig. 5. HVSR results at recording sites located in the not fractured zone, stratigraphic sequence, shear wave velocity profile and comparison of experimental spectral ratios with 1-D theoretical modelling.

chose the recording sites in order to sample the area as uniformly as possible. Moreover, several recording sites where chosen on a linear deployment for investigating the role of the fractures in the HVSR behaviour. Figure $2 \mathrm{c}$ shows the geological setting of the investigated area.

The HVSR curves obtained identify three different zones. In particular, we can identify a region (Fig. 5, sites \#5, \#6, \#7, \#25, \#27) where the HVSR peaks around a stable frequency of about $1.5 \mathrm{~Hz}$. These fundamental peaks may be generally associated with the interface separating the $\mathrm{BC}$ layer from the GL. The presence of the BC layer gives rise to a velocity inversion since it has a lower shear wave velocity with respect to the overlying UCL formation. This causes the HVSR values to drop below 1 over a wide frequency range (e.g. Castellaro and Mulargia 2009; Panzera et al., 2011b). The origin of the resonance peak was confirmed by carrying out 1-D modelling, computing synthetic HVSR curves (Fig. 5). To compute the synthetic spectral ratios, we considered that ambient vibration wavefields can be represented by the superimposition of random multi-modal plane waves moving in all the directions at the surface of a flat 1-D layered viscoelastic solid, as in the Herrmann (2002) formulation. These waves are assumed to correspond to Rayleigh waves in the fundamental mode (Fah et al., 2001), including also the presence of Love waves (Bonnefoy-Claudet et al., 2008), generated by a distribution of random independent point sources located at the surface of the Earth (Lunedei and Albarello, 2009). Although the contribution of higher modes is relatively small, we extended the modal summation up to the fifth mode. When modelling the HVSR, we applied initial constraints on the thicknesses and elastic parameters of the layers using borehole logs data to obtain approximate values 

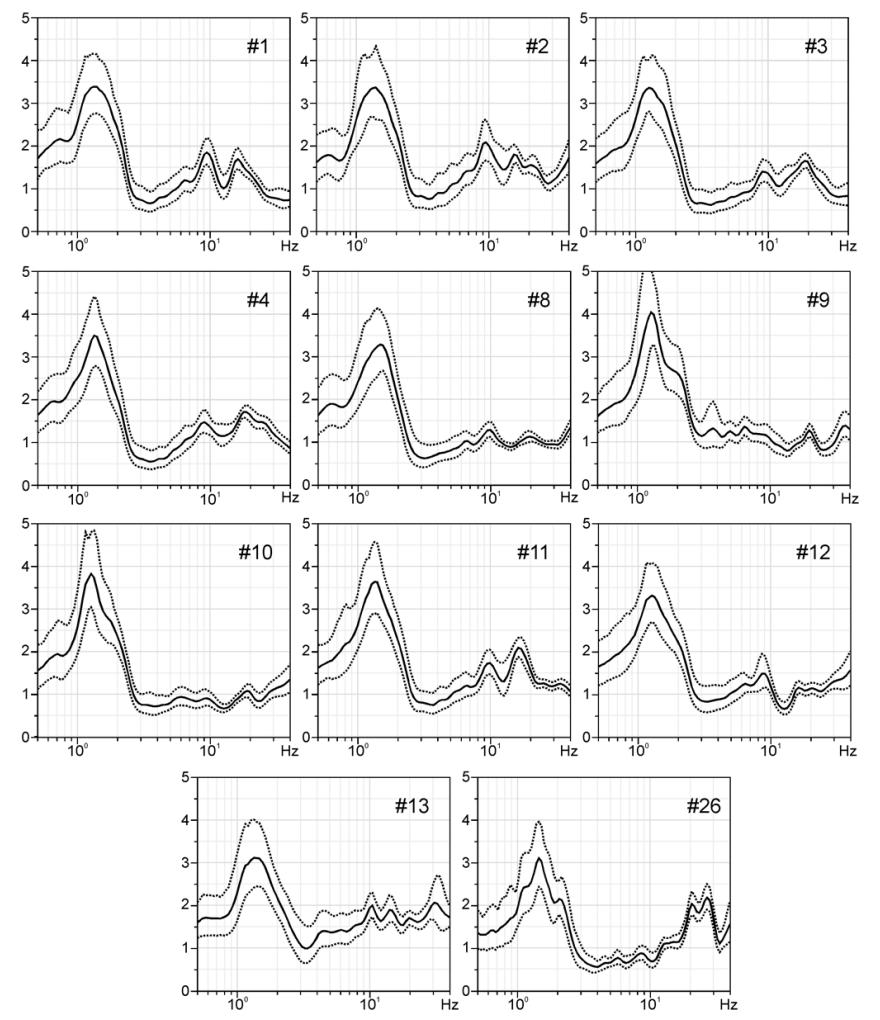

Fig. 6. HVSR results at recording sites located along the fractured zone in the cliff area.

of layer thicknesses and rock densities. Seismic velocity values were also utilised from a separate preliminary study undertaken in the same area using the ReMi, MASW and refraction methods (Panzera et al., 2011c).

The sites close to the cliff edge and all around the identified fractures (Fig. 6, \#1, \#2, \#3, \#4, \#8, \#9, \#10, \#11, $\# 12$, \#13, \#26) present a similar behaviour to the one described above, but with a slightly different feature at the highfrequency. In general, in all the records (Fig. 6) we observe a clear and predominant peak at around $1.5 \mathrm{~Hz}$ which is associated with the interface between BC and GL. Several peaks, showing a slight increase of the amplitude on the HVSR, are also evident at higher frequency $(>9.0 \mathrm{~Hz})$. The fact that these peaks are not visible in the unfractured region leads us to postulate that they may be associated with the presence of fractures and of blocks almost detached from the cliff and therefore free to oscillate.

The sites in the rockfall area show a different HVSR behaviour (Fig. 7) with respect to the measurements taken on the plateau. In this area it is possible to identify HVSRs showing bimodal dominant peaks at low frequency, in the range of $1.0-3.0 \mathrm{~Hz}$, as well as pronounced peaks at about $3.0 \mathrm{~Hz}$ and at frequency higher than $9.0 \mathrm{~Hz}$ (Fig. 7). Trying to interpret these observations within a geological framework following the section in Fig. 5, the bimodal peaks at low frequency $(1.0-3.0 \mathrm{~Hz})$ can, in our opinion, be associated with
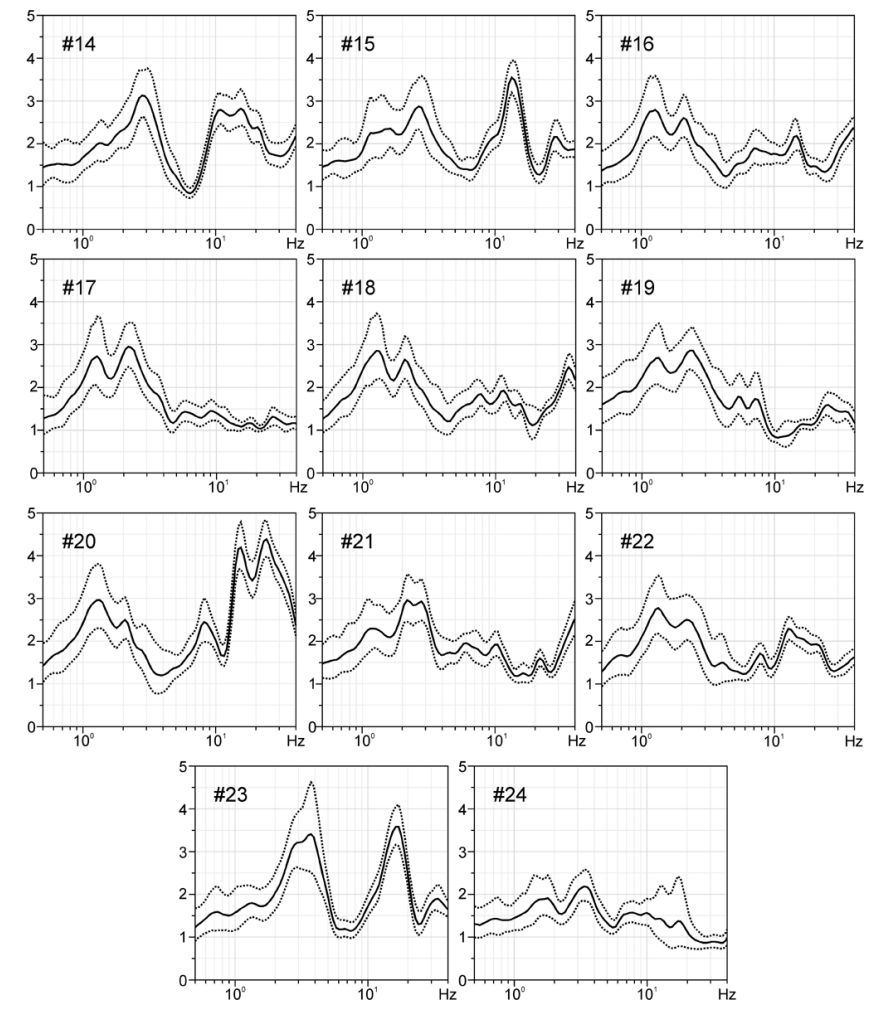

Fig. 7. HVSR results at recording sites located in the landslide zone.

the contact between the rockfall and detritus unit and the BC formation, as well as to the interface between $\mathrm{BC}$ and the underlying GL formation. It is interesting to observe that such bimodal peaks are not observed in the measurement sites located in the southern part of the landslide zone (\#14, \#23, \#24). It therefore seems that the thickness of the rockfall and detritus deposits plays an important role, pointing out the existence of bimodal peaks at low frequency when its thickness is of the order of tens of meters, whereas only the fundamental frequency associated to the contact BC/GL appears when the detritus thickness decreases. Peaks observed at frequencies greater than $9.0 \mathrm{~Hz}$, as previously described, can be associated with detached blocks almost free to oscillate.

In Fig. 8a we summarize the above described results into a tentative draft profile, located as shown in Fig. 2b, which illustrates the main geological features and hypothesizes the shape of the landslide body. The bottom panel (Fig. 8b) shows a 2-D diagram obtained by combining all the ambient noise measurements along the profile, namely the HVSR spectra shown in Panel c of Fig. 8. Below the sites \#5 and $\# 25$, the main peaks can be associated with a sequence of layers which have different shear wave velocities and show the presence of an evident velocity inversion. Moving along the profile from measurement point \#4 to \#1, it is interesting to observe the increasing amplitude of the HVSR at frequencies greater than $6.0-7.0 \mathrm{~Hz}$. It can also be noticed that, especially between 50 and $60 \mathrm{~m}$ along the profile (sites \#1, \#2 and 

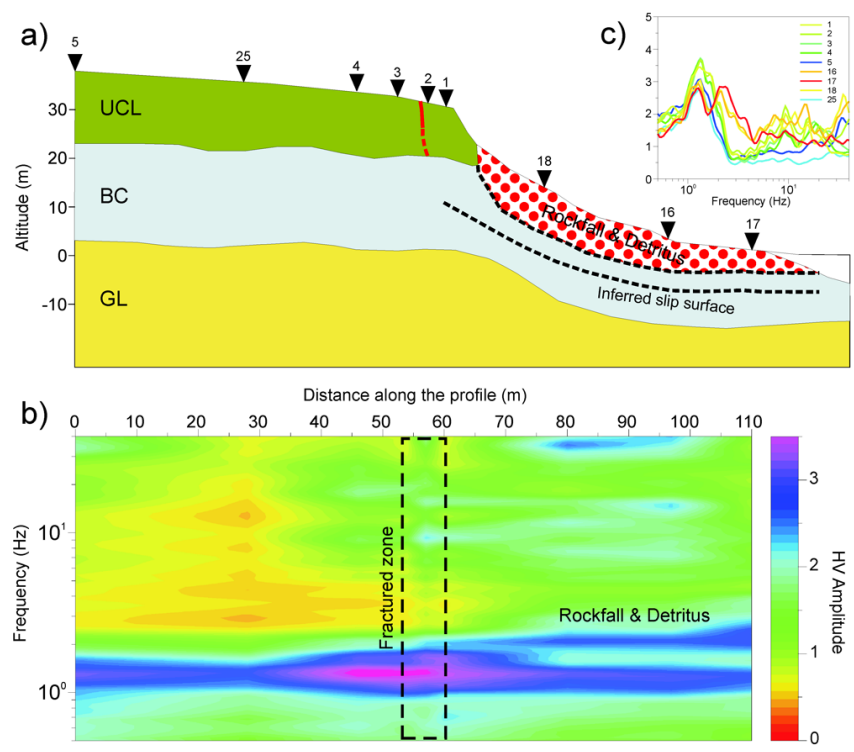

Fig. 8. (a) Cross section along the A-B profile in Fig. 2c; (b) 2-D diagram obtained combining all the ambient noise measurements along the profile as a function of distance (x-axis) and frequency (y-axis); and (c) HVSR results at the recording sites located across the profile.

\#3), the influence of the fracture zone is evident (see dashed area in Fig. 8b). This is associated with the presence of the mapped main fracture (marked in red in the top panel) and the vibrational mode of the almost detached blocks. Along the cross section, at distances ranging from 60 to $100 \mathrm{~m}$, it is possible to note both the presence of the bimodal peak associated with the two interfaces, detritus/BC and BC/GL, as well as the high frequency peaks most probably associated with the vibration of large blocks that have been detached from the cliff face and are now partially or totally included in the $\mathrm{BC}$.

\subsection{Directional effects from HVSR and polarization analysis}

The existence of directional effects in the site response was investigated by rotating the horizontal components of the spectral ratios obtained at each measurement site by steps of $10^{\circ}$ starting from $0^{\circ} \mathrm{N}$ to $180^{\circ} \mathrm{N}$ (Fig. 9). We observe that the rotated spectral ratios obtained in the cliff fracture zones show clear directional effects with an angle of about $40^{\circ}-$ $60^{\circ} \mathrm{N}$ in all of the considered frequency range (first row in Fig. 9), although some variability in azimuth is observed at high frequency $(>9 \mathrm{~Hz})$ at site \#13. On moving away from the cliff edge, the rotated HVSRs show a slight change of the directional resonance angle (second row in Fig. 9) and an amplitude decrease of the rotated spectral ratios at high frequency. Such a behavior could be linked to the increase of rock stiffness and the reduction of the amount of blocks free to oscillate. Finally, it is evident that the directionality pattern observed in the rotated HVSRs performed on the landslide body is quite complex (third row in Fig. 9). The general trend has a prevailing direction of about $40^{\circ}-60^{\circ} \mathrm{N}$ at low frequency $(1.0-9.0 \mathrm{~Hz})$, similar to what is observed in the fractured zone, whereas different resonant frequencies and directions that could be ascribed to the vibration of smaller blocks can be observed at higher frequencies $(9.0-40.0 \mathrm{~Hz})$.

Furthermore, we obtained a direct estimate of the polarization angle through the full use of the three-component vector of the noise wavefield. Signals at each site were band-pass filtered in three frequency bands $1.0-40.0 \mathrm{~Hz}, 1.0-10.0 \mathrm{~Hz}$ and $10.0-40.0 \mathrm{~Hz}$. The last two frequency bands, in particular, were selected in order to distinguish between properties of low and high frequency components of the signal. It seems evident that the prevailing angle of directional site effects observed in the HVSR, especially in the fractured and in the landslide zone, appear constant in the NE direction in the range $1.0-10.0 \mathrm{~Hz}$, whereas directional effects become more randomly distributed at frequency greater than $10 \mathrm{~Hz}$ (see Fig. 9). Some examples of the results of noise polarization analysis from recording sites on both the cliff and the landslide are shown in Fig. 10. Considering the three selected frequency bands, it is clear that the maxima of the horizontal polarization occurs in the northeast direction, although in some cases (see for instance \#22) the high frequency directionality is more complex. As observed by Burjánek et al. (2010), high-frequency ground motion can indeed be controlled by the vibration of smaller blocks that imply both different resonant frequencies and directions. In Fig. 11, some examples of Fourier spectra, showing the presence of spectral peaks in the vertical component at the same frequency of the maxima of horizontal components of motion, are reported to support the existence of rocking mode vibration at high frequency.

The polarization observed for the sites located away from the unstable areas (see middle panel in Fig. 10) show a trend with more dispersed and variable directions. The boundaries of the landslide area therefore appear well defined by the polarization pattern, and as postulated by Kolesnikov et al. (2003) the landslide activity is characterized by strong horizontal polarization in a broad frequency band. In our study, a tendency seems evident for the entire landslide body to generally vibrate with a northeast azimuth and, accordingly, during a strong earthquake the ground motion would be amplified in this direction. Studies of Burjánek et al. $(2010,2012)$ point out that the ambient noise polarization is at about a 90-degree angle to the observed fractures which are perpendicular to the sliding direction. In the present study the polarization angle is parallel to the opening cracks, which appears in contrast to the above mentioned results. A possible explanation of our findings is that there exists a prevailing northeasterly sliding direction of the landslide body which is strongly affecting the polarization direction, especially in the $1-10 \mathrm{~Hz}$ frequency range. 

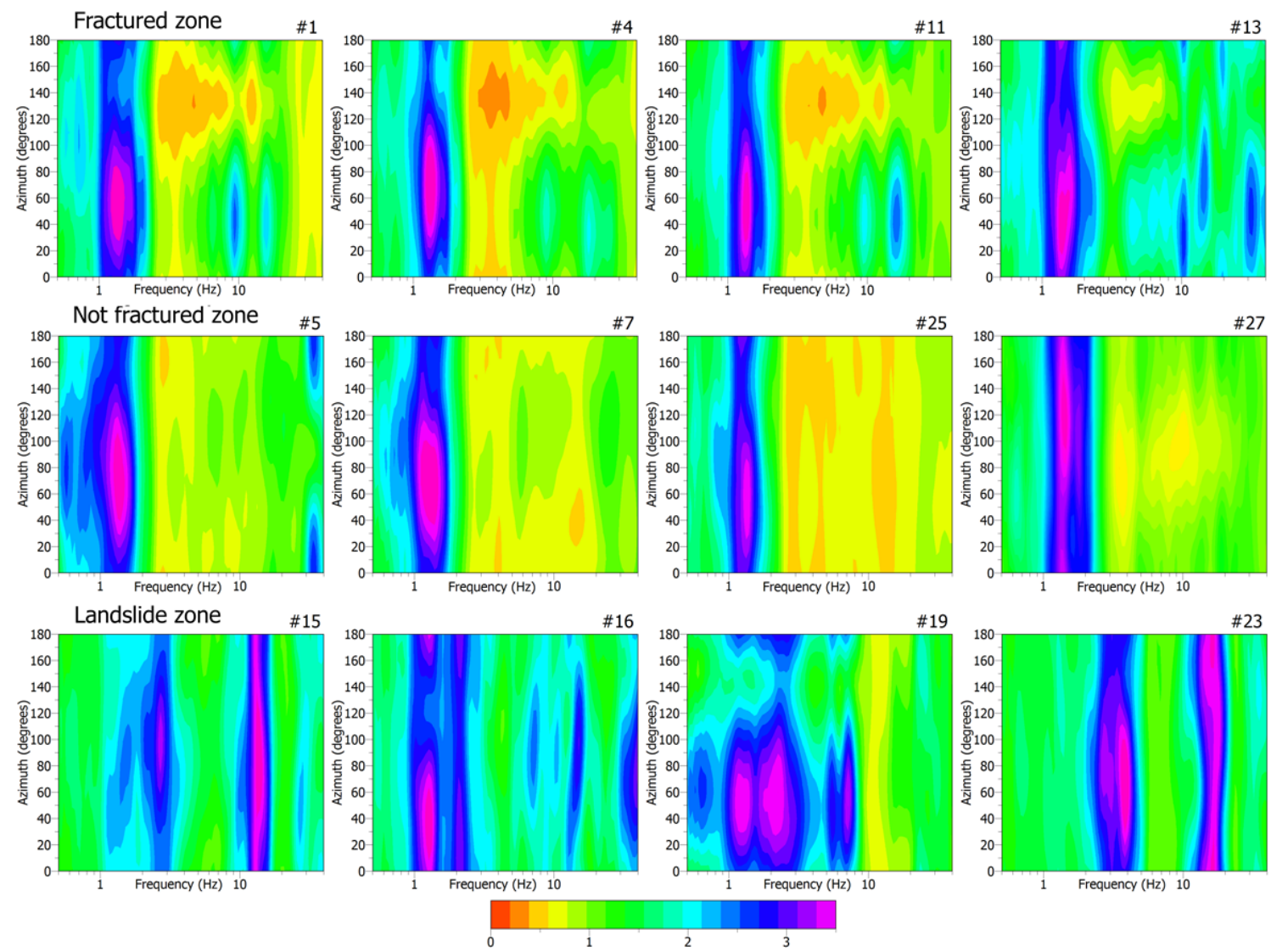

Fig. 9. Examples of the contours of the geometric mean of the spectral ratios as a function of frequency (x-axis) and direction of motion (y-axis) obtained at selected ambient noise recording sites.

\section{Concluding remarks}

This paper presents a preliminary field study in the Xemxjia Bay area aiming to highlight the importance of evaluating the local seismic response in presence of the slope instabilities related to landslide hazard. In particular, large cliff-parallel fractures that could cause cliff-edge collapse and main unstable boulders were identified, mapped and photographed in order to document the present-day situation. The most diffuse collapse mechanism is represented by rockfalls, toppling and retrogressive sliding of small to large rocks. These processes are most likely induced by the different stiffness of the clay and the overlying limestone. Recent studies by M. Soldati (personal communication, 2011) have pointed out that there is no evidence of measured movements after rain or dry periods. We therefore think that the fracturing is not induced by weathering and erosion at the cliff edge. In our opinion, following the outcomes of noise measurements, the presence of the clay formation develops a sliding surface and produces tension stresses at the top of the UCL. Thus, cracks expand due to the ultimate tensile strength of the formation, defining blocks on the top of both cliff and hill which are affected by collapse mechanisms (Lollino and Pagliarulo, 2008).
It is known that seismically-induced ground acceleration can lead in some cases to landsliding and block detachment that therefore represent a considerable problem for engineering geology (Fell et al., 2008). In areas prone to severe ground shaking, the effect of seismically-induced landslides on human lives and facilities can add further damage to that directly connected to the shaking (e.g. Jibson et al., 2000), as experienced in several earthquakes of moderate and large magnitude such as in the recent $M_{\mathrm{w}}=6.3$ earthquake in Christchurch (New Zealand, 22 February 2011), the $M_{\mathrm{w}}=6.2$ L'Aquila earthquake (Italy, 6 April 2009) and the $M_{\mathrm{w}}=7.9$ Wenchuan earthquake (China, 12 May 2008). The seismic history of the Maltese Islands is adequately documented since around 1500 (Galea, 2007). During this period, the islands have suffered earthquake damage exceeding EMS-98 intensity V on seven occasions $(1542,1693,1743$, $1856,1861,1911,1923)$, and the occurrence of landslides has been reported on several occasions (e.g. 1693 earthquake from Ellul, 1993).

The Xemxija unstable area is characterized by the presence of numerous blocks and boulders along the slopes and cliff base, supporting the idea that the area is prone to a severe landslide risk. The instability processes that could be 


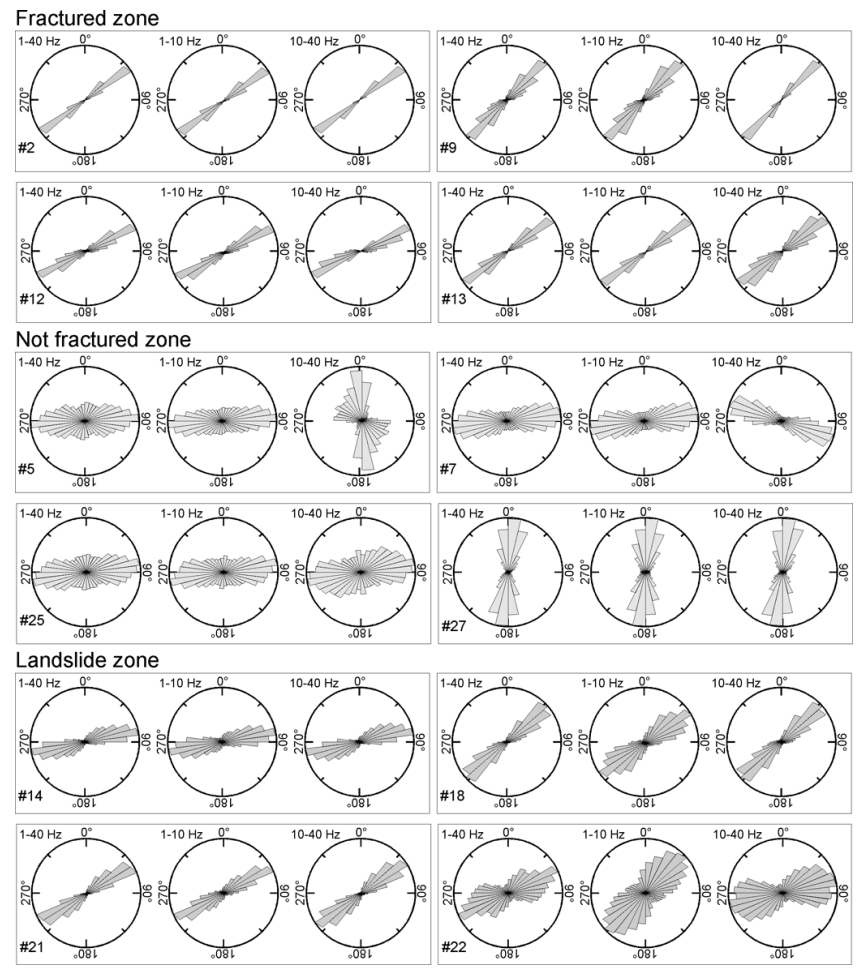

Fig. 10. Examples of rose diagrams at representative ambient noise recording sites.

potentially triggered are linked to both slow mass movements, which might normally occur over tens or hundreds of years, and sudden rockfall in the case of ground shaking due to moderate-to-strong earthquake activity. To better understand the situation, the most important discontinuities, both in the coastal cliff area and the hill, were identified and mapped, focusing in particular on the main unstable rock masses which might be displaced even in case of moderate earthquakes.

The available literature data and recent instrumental observations indicate that the dynamic response of potentially unstable slopes to seismic shaking can be very complex. In particular, there is evidence that seismic ground motion on landslide slopes can be considerably amplified, and such amplification has a directional character (Moore et al., 2011). Such directional effects were seen to be related with topographic, lithologic and structural factors as well as normal mode rock slope vibration (e.g. Del Gaudio et al., 2008; Burjánek et al., 2012). The NE part of Xemxija Bay, in which there is major evidences of slope instability, was studied in detail through ambient noise measurements. The results of horizontal-tovertical spectral ratio measurements indicate that this method could be useful for the recognition of site response directivity phenomena. The use of noise measurements pointed out the existence of three different zones: a stable zone, in which the HVSRs show only a dominant peak at about $1.5 \mathrm{~Hz}$, linked to the presence of the $\mathrm{BC}$ in the shallow lithologic sequence;

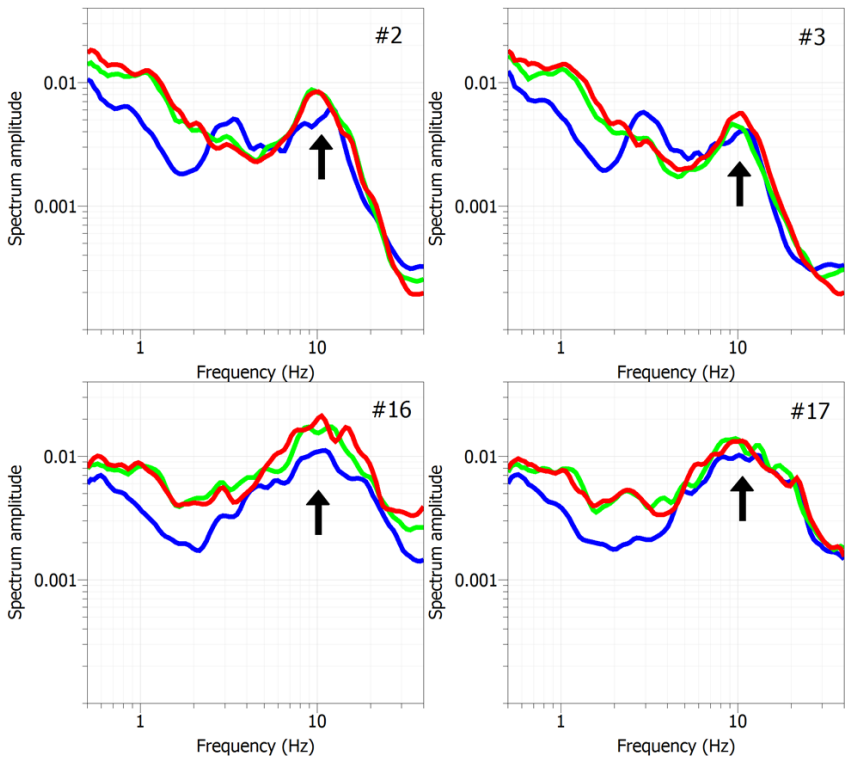

Fig. 11. Examples of Fourier spectra at representative ambient noise recording sites along the profile shown in Fig. 8. Blue, red and green lines refers to the vertical, $\mathrm{N}-\mathrm{S}$ and $\mathrm{E}-\mathrm{W}$ components of motion. The black arrow indicates the frequency range showing the rocking mode vibration.

a second zone, close to the cliff area, characterized by the presence of spectral ratio peaks linked to both the presence of shallow lithotypes such as the BC and the UCL, as well as to the existence of the fractures in the rock; and a third zone on the landslide body, which puts into evidence the presence of an active slip surface inside the soft clayey material that allows the slow sliding of the upper portion of $\mathrm{BC}$ formation. Moreover, the experimental data highlight the existence of directivity phenomena, affecting in particular the slope areas, centered in the northeastern direction, that seem to be influenced by the simultaneous action of geological factors as well as fractures and block vibrations linked to the landslide activity.

Acknowledgements. This work was performed in the frame of the executive program for cultural collaboration between Italy and Malta supported by the Embassy of Malta in Rome and the Ministero degli Affari Esteri Italiano. The authors are grateful to the handling editor Oded Katz as well as to Marco Mucciarelli and to an anonymous reviewer for the useful suggestions that improved the quality of present study.

Edited by: O. Katz

Reviewed by: M. Mucciarelli and one anonymous referee 


\section{References}

Bonnefoy-Claudet, S., Cornou, C., Bard, P-Y., Cotton, F., Moczo, P., Kristek, J., and Fäh, D.: H/V ratio: a tool for site effects evaluation. Results from 1-D noise simulations, Geophys. J. Int., 167, 827-837, doi:10.1111/j.1365-246X.2006.03154.x, 2006.

Bonnefoy-Claudet, S., Köhler, A., Cornou, C., Wathelet, M., and Bard, P-Y.: Effects of Love waves on microtremor H/V ratio, Bull. Seism. Soc. Am., 98, 288-300, 2008.

Burjànek, J., Gassner-Stamm, G., Poggi, V., Moore, J. R., and Fäh, D.: Ambient vibration analysis of an unstable mountain slope, Geophys. J. Int., 180, 820-828, doi:10.1111/j.1365246X.2009.04451.x, 2010.

Burjánek, J., Moore, J. R., Molina, F. X. Y., and Fäh, D.: Instrumental evidence of normal mode rock slope vibration, Geophys. J. Int., 188, 559-569, 2012.

Castellaro, S. and Mulargia, F.: The Effect of Velocity Inversions on H/V, Pure Appl. Geophys., 166, 567-592, doi:10.1007/s00024009-0474-5, 2009.

Coratza, P., Bruschi, V. M., Piacentini, D., Saliba, D., and Soldati, M.: Recognition and Assessment of Geomorphosites in Malta at the Il Majjstraal Nature and History Park, Geoheritage 3, 175185, doi:10.1007/s12371-011-0034-0., 2011.

Del Gaudio, V. and Wasowski, J.: Advances and problems in understanding the seismic response of potentially unstable slopes, Eng. Geol., 122, 73-83, 2011.

Del Gaudio, V., Coccia, S., Wasowski, J., Gallipoli, M. R., and Mucciarelli, M.: Detection of directivity in seismic site response from microtremor spectral analysis, Nat. Hazards Earth Syst. Sci., 8, 751-762, doi:10.5194/nhess-8-751-2008, 2008.

Doody, P., Ferreira, M., Lombardo, S., Lucius, I., Misdorp, R., Niesing, H., Salman, A., and Smallegange, M.: Living with coastal erosion in Europe: sediment and space for sustainability: Results from the EUROSION study, European Commission, Luxembourg, 38, ISBN 92-894-7496-3, 2004.

Ellul, M.: The Earthquake of 1693 - A historical survey, in: Mdina and the earthquake of 1693, Can J Azzopardi Heritage Books, Malta, 1993.

Fäh, D., Kind, F., and Giardini, D.: A theoretical investigation on H/V ratios, Geophys. J. Int., 145, 535-549, 2001.

Farrugia, M. T.: Coastal erosion along northern Malta: geomorphological processes and risks, Geogr. Fis. Dinam. Quat., 31, 149160, 2008.

Fell, R., Corominas, J., Bonnard, C., Cascini, L., Leroi, E., and Savage, W. Z.: On behalf of the JTC- 1 Joint Technical Committee on Landslides and Engineered Slopes, 2008. Guidelines for landslide susceptibility, hazard and risk zoning for land use planning, Eng. Geol., 102, 85-98, 2008.

Foresi, L. M., Bonomo, S., Caruso, A., Di Stefano, E., Salvatorini, G., and Sprovieri, R.: Calcareous plankton high resolution biostratigraphy (foraminifera and nannofossils) of the uppermost Langhian-lower Serravallian Ras Il-Pellegrin section (Malta), Rev. Ital. Paleontol. Stratigr., 108, 195-210, 2002.

Galea, P.: The Seismic History of the Maltese Islands and considerations on seismic risk, Ann. Geophys., 50, 725-740, 2007, http://www.ann-geophys.net/50/725/2007/.

Hart, M. G.: Geomorphology: Pure and Applied, Allen \& Unwin Ltd, London, 228 pp., 1986.

Herrmann, R. B.: Computer programs in seismology, Vol. 4, St. Louis University, 2002.
Ibs-Von Seth, M. and Wohlenberg, J.: Microtremor measurements used to map thickness of soft sediments, Bull. Seism. Soc. Am., 89, 250-259, 1999.

Jacobs, E., Weissert, H., Shields, G., and Stille, P.: The Monterey event in the Mediterranean: A record from shelf sediments of Malta, Paleoceanography, 11, 717-728, 1996.

Jibson, R. W., Harp, E. L., and Michael, J. A.: A method for producing digital probabilistic seismic landslide hazard maps, Eng. Geol., 58, 271-289, 2000.

Jurkevics, A.: Polarization analysis of three component array data, Bull. Seism. Soc. Am., 78, 1725-1743, 1988.

Kienel, U., Rehfeld, U., Bellas, S. M., and Kohring, R.: The Miocene Blue Clay Formation of the Maltese Islands: Sequencestratigraphic and paleoceanographic implications based on calcareous nannofossil stratigraphy and calcareous dinoflagellate cysts, J. Nanoplankton Res., 17, 69-70, 1995.

Kolesnikov, Yu. I., Nemirovich-Danchenko, M. M., Goldin, S. V., and Seleznev, V. S.: Slope stability monitoring from microseismic field using polarization methodology, Nat. Hazards Earth Syst. Sci., 3, 515-521, doi:10.5194/nhess-3-515-2003, 2003.

Konno, K. and Ohmachi, T.: Ground-motion characteristics estimated from spectral ratio between horizontal and vertical components of microtremor, Bull. Seism. Soc. Am., 88, 228-241, 1998.

Lermo, J. and Chavez-Garcia, F. J.: Site effect evaluation using spectral ratio with only one station, Bull. Seism. Soc. Am., 83, 1574-1594, 1993.

Lollino, P. and Pagliarulo, R.: The interplay of erosion, instability processes and cultural heritage at San Nicola island (Tremiti archipelago, southern Italy), Geogr. Fis. Dinam. Quat., 31, 161169, 2008.

Lunedei, E. and Albarello, D.: On the seismic noise wavefield in a weakly dissipative layered Earth, Geophys. J. Int., 177, 10011014, 2009.

Magri, O., Mantovani, M., Pasuto, A., and Soldati, M.: Geomorphological investigation and monitoring of lateral spreading along the North west coast of Malta, Geogr. Fis. Dinam. Quat., 31, 171-180, 2008.

Malischewky, P. G. and Scherbaum, F.: Love's formula and H/V ratio (ellipticity) of Rayleigh waves, Wave Motion, 40, 57-67, 2004.

MEPA (Malta Environment and Planning Authority, Mapping Unit): Xemxjia bay area map 1:2500, 2004.

Moore, J. R., Gischig, V., Burjanek, J., Loew, S., and Fäh, D.: Site effects in unstable rock slopes: dynamic behavior of the Randa instability (Switzerland), Bull. Seism. Soc. Am., 101, 31103116, 2011.

Mourik, A.A., Abels, H. A., Hilgen, F. J., Di Stefano, A., and Zachariasse, W. J.: Improved astronomical age constraints for the Middle Miocene Climate Transition based on high-resolution stable isotope records from the central Mediterranean Maltese Islands, Paleoceanography, 26, PA1210, doi:10.1029/2010PA001981, 2011.

Nogoshi, M. and Igarashi, T.: On the propagation characteristics of microtremors, J. Seism. Soc. Japan, 23, 264-280, 1970.

Panzera, F., Lombardo, G., and Rigano, R.: Evidence of topographic effects analysing ambient noise measurements: the study case of Siracusa, Italy, Seismol. Res. Lett., 82, 385-391, doi:10.1785/gssrl.82.3.385, 2011a. 
Panzera, F., Rigano, R., Lombardo, G., Cara, F., Di Giulio, G., and Rovelli, A.: The role of alternating outcrops of sediments and basaltic lavas on seismic urban scenario: the study case of Catania, Italy, B. Earthq. Eng., 9, 411-439, doi:10.1007/s10518-0109202-x, 2011b.

Panzera, F., Pace, S., D’Amico, S., Galea, P., and Lombardo, G.: Preliminary results on the seismic properties of main lithotypes outcropping on Malta, GNGTS $30^{\circ}$ Convegno Nazionale, Mosetti tecniche grafiche, Trieste, 306-308, 2011c.

Pasuto, A. and Soldati, M.: Rock spreading, in: Landslide recognition: identification, movement and causes, edited by: Dikau, R., Brunsden, D., Schrott, L., and Ibsen, M. L., Wiley, Chichester, 122-136, 1996.

Pedley, H. M., House, M. R., and Waugh, B.: The geology of the Pelagian block: the Maltese Islands, in: The Ocean Basin and Margins, edited by: Narin, A. E. M., Kanes, W. H., and Stehli, F. G., Vol. 4B: The Western Mediterranean, Plenum Press, London, 417-433, 1978.

Pedley, H. M., Clark, M., and Galea, P.: Limestone isles in a cristal sea: the geology of the Maltese islands, P.E.G. Ltd, ISBN: 999090-318-2, 2002.

Scherbaum, F., Hinzen, K. G., and Ohrnberger, M.: Determination of shallow shear wave velocity profiles in the Cologne, Germany area using ambient vibrations, Geophys. J. Int., 152, 597-612, 2003.
SESAME: Guidelines for the implementation of the H/V spectral ratio technique on ambient vibrations: Measurements, processing and interpretation. SESAME European Research Project WP12, deliverable D23.12, 2004; available at: http://sesame-fp5.obs. ujf-grenoble.fr/Deliverables2004 (last access: 13 January 2009), 2004.

Soldati, M., Buhagiar, S., Coratza, P., Pasuto, A., and Schembri, J. A.: Integration of geomorphological environment and cultural heritage: a key issue for present and future times, Geogr. Fis. Din. Quat., 31, 95-96, 2008.

Spudich, P., Hellweg, M., and Lee, W. H. K.: Directional topographic site response at Tarzana observed in aftershocks of the 1994 Northridge, California, earthquake: implications for mainshock motions, Bull. Seism. Soc. Am., 86, 193-208, 1996.

Various Authors: Geological Map of the Maltese Island, Sheet 1 Malta - Scale 1:25,000, Oil Exploration Directorate, Office of the Prime Minister, Malta, 1993.

Young, A. P., Adams, P, N., O'Reilly, W. C., Flick, R. E., and Guza, R. T.: Coastal cliff ground motions from local ocean swell and infragravity waves in southern California, J. Geophys. Res., 116, C09007, doi:10.1029/2011JC007175, 2011. 